\title{
Peripheral markers of neurochemical function among workers exposed to styrene
}

\author{
Harvey Checkoway, Lucio G Costa, Janice Camp, Teresa Coccini, William E Daniell,
} Russell L Dills

\begin{abstract}
A cross sectional study of biological markers of neurochemical function in peripheral blood cells, and self reported nervous system symptoms, was conducted among 60 workers exposed to styrene in three reinforced plastics plants and 18 reference workers not exposed to styrene or other solvents. Concentrations of styrene in the air at the plants ranged from $<1$ to $160 \mathrm{ppm}$. Biomarkers of neurochemical function measured were: sigma receptor binding in lymphocytes, monoamine oxidase type $B$ (MAO-B) activity in platelets, and serotonin uptake by platelets. Blood styrene concentration was used as the exposure index to take account of the use of protective equipment and dermal uptake. Four blood styrene exposure groups were defined as: non-exposed (reference) and exposed to $<0.05,0.05-0.19$, and $\geqslant 0.20 \mu \mathrm{g} / \mathrm{ml}$. The prevalences of headache, dizziness, light headedness, fatigue, irritability, memory loss, and feeling "drunk" at work increased with increasing blood styrene concentration. No effect on sigma receptor binding was seen. A slight positive correlation was found for uptake of serotonin, which has been used as an exposure related effect indicator in previous studies of workers exposed to solvents. The MAO-B activity decreased with increasing blood styrene concentration; the mean (SE) MAO-B values for the four groups were $34 \cdot 2(3 \cdot 0), 28 \cdot 1(5 \cdot 3), 20 \cdot 1$ $(4 \cdot 8)$, and $16.9(7 \cdot 7) \mathrm{pmol} / 10^{7}$ cells $/ \mathrm{min}$. The MAO-B activity also correlated negatively with the number of reported nervous system symptoms, whereas no associations were seen between prevalence of symptoms and either
\end{abstract}

Department of Environmental Health, SC-34, University of Washington, School of Public Health and Community Medicine, Seattle, WA 98195, USA H Checkoway, L G Costa, J Camp, W E Daniell, R L Dills

Institute of Pharmacology, University of Pavia Medical School, Pavia, Italy T Coccini serotonin uptake or sigma receptor binding. The findings for MAO-B activity are consistent with previously reported experimental data, and suggest that MAO-B may be a useful marker of styrene neurotoxicity.

The neurotoxic effects of occupational exposure to styrene have been evaluated by numerous approaches, including assessments of prevalence of central nervous system (CNS) symptoms, ${ }^{1-3}$ psychomotor reaction tests, ${ }^{4-7}$ and electroencephalography. ${ }^{189}$ Toxicity of the CNS from occupational exposures in excess of 100 parts per million (ppm) in air is a well accepted phenomenon, although there is debate about effects at lower concentrations in the workplace. ${ }^{10}$ Data from a recent study in Sweden suggest that exposure to a range of 10-25 ppm may cause reversible neuropsychiatric symptoms, including disturbances of memory and concentration, unprovoked irritability, and decreased libido. ${ }^{11}$

The precise mechanism of styrene induced neurotoxicity is not known. One proposed pathway is impairment of dopaminergic activity in the brain, possibly mediated by diminished dopamine modulation of pituitary function. ${ }^{12}$ Evidence exists from animal experiments and human studies to support a dopamine mediated effect of styrene related neurotoxicity. Dopamine depletion has been detected in the brains of dosed rabbits, ${ }^{13} 14$ and an increase in dopamine receptor binding in rat brain striatum, possibly as a compensatory reaction to dopamine depletion, has been reported. ${ }^{15}$ Dose related increases in serum prolactin and thyroid stimulating hormone concentrations among workers exposed to styrene have been interpreted as supportive of a toxic mechanism involving depletion of tuberinfundibular dopamine. ${ }^{12} 16$

The principal objective of this research was to evaluate the utility of several peripheral blood cell parameters of neurochemical function as biomarkers of effect among workers in the fibreglass reinforced plastics (FRP) industry who are exposed to styrene at relatively low concentrations (below the $50 \mathrm{ppm}$ currently permissible eight hour time weighted average exposure limit in the United States). This involved evaluating the relations between biomarker 
levels, styrene exposures, and the prevalence of self reported CNS symptoms.

Three markers of neurochemical function were measured: type B monoamine oxidase (MAO-B) activity in platelets, serotonin uptake in platelets, and sigma receptor binding in lymphocytes. MAO-B is a microsomal enzyme that catabolises dopamine and other sympathetic amines. Platelet MAO-B activity is used clinically as a marker of the pharmacological effects of MAO inhibitors, such as in the treatment of Parkinson's disease, because it appears to reflect reliably activity in nervous tissue. ${ }^{17}$ To our knowledge, platelet MAO-B activity has not been evaluated previously as a biomarker of effects of occupational exposures, although decreased brain activity has been found in styrene treated rats. ${ }^{18}$ Serotonin is a neurotransmitter with a wide range of nervous system functions, including the potentiation of dopamine release.${ }^{19}$ Serotonin uptake in platelets is stimulated by oxidative stress, ${ }^{20}$ and increased rates of uptake by platelets have been found among workers exposed to organic solvents in paints. ${ }^{212}$ Previously we have attempted to measure dopamine $\mathrm{D}_{2}$ receptor binding in lymphocytes of styrene treated animals and exposed workers in an effort to examine dopamine depletion as a potential mechanism of toxicity. A study among FRP boat plant workers indicated a positive correlation between styrene exposure and lymphocyte binding using ${ }^{3} \mathrm{H}-$ spiperone as the presumed ligand for $\mathrm{D}_{2}$ receptors. ${ }^{23}$ Subsequent pharmacological binding studies indicated, however, that binding to sigma receptors rather than $\mathrm{D}_{2}$ receptors was being measured by ${ }^{3} \mathrm{H}-$ spiperone. ${ }^{24}$ Sigma receptors are non-dopaminergic, non-opioid receptors which have been linked with various psychoses, although their normal physiological functions have not been established. ${ }^{25} 26$ Despite the lack of a clear hypothesis for measurement of sigma receptors in lymphocytes, the positive findings of the pilot study and a case report of psychosis possibly linked to exposure to styrene ${ }^{27}$ prompted us to pursue this line of investigation.

\section{Materials and methods \\ STUDY SUBJECTS}

A cross sectional survey was conducted in May 1989 at three fibreglass reinforced plastic plants in western Washington state. The survey was conducted during midweek, on Wednesday and Thursday. The study group consisted of 60 workers exposed to styrene and 18 machine assembly workers from one of the plants who worked in a building separated from the styrene operation and were thus not exposed to styrene or to other organic solvents. (The absence of styrene exposure in the reference workers was confirmed by air monitoring and measurements of blood styrene concentration.) The exposed group included 44 men and 16 women, age range $20-47$ years; and there were
14 male and four female reference workers, age range 22-51 years. Informed consent forms explaining the purposes and procedures of the study were given to the workers. Data on demographic variables, height, weight, employment history, smoking, alcohol use, and medical history including prevalence of CNS symptoms, were obtained by means of a self administered questionnaire presented to workers during the workshift.

\section{EXPOSURE ASSESSMENT}

Full shift exposure monitoring of styrene was performed using personal breathing zone passive dosimeters (SKC Anasorb, model No 530-11). Eight hour time weighted average exposures were determined by gas chromatography according to the method described by the National Institute of Occupational Safety and Health (NIOSH) ${ }^{28}$

Urine samples for measurement of the styrene metabolites, mandelic and phenylglyoxylic acids were collected during the early hours of the workshift. The assay used was a modification of the method of Guillemin and Bauer ${ }^{29}$ with capillary gas chromatography.$^{30}$ Concentrations of styrene in venous blood were measured by headspace gas chromatography using automatic cryogenic focusing and high resolution capillary chromatography. ${ }^{31}$ In this assay an automated headspace sampler (HewlettPackard model 19395A) is directly interfaced to the capillary gas chromatographic column (DB-Wax; J \& W Scientific) via an integral liquid nitrogen concentrator loop; analytes are eluted using a temperature programme, and detected by flame ionisation.

NEUROCHEMICAL FUNCTION ASSAYS

Platelets were isolated from $10 \mathrm{ml}$ venous blood samples collected in EDTA treated tubes by the method of Hamet et al ${ }^{32}$ and were prepared for the MAO-B assay according to techniques described by Corash et al. ${ }^{33}$ Blood samples were centrifuged for 10 minutes at $200 \mathrm{~g}$ to obtain the platelet rich plasma (PRP). The PRP was lysed with $5 \mathrm{mM}$ of tris buffer (pH 7.4), homogenised, and centrifuged at $16000 \mathrm{~g}$ for 10 minutes. The supernatant was discarded and $\mathrm{Na}^{+} / \mathrm{K}^{+}$buffer was added in a 3:1 ratio. The PRP was removed and washed twice with the same buffer. After centrifugation at $700 \mathrm{~g}$ for 30 minutes, the platelet pellet was resuspended in buffer and washed twice. The final pellet, obtained after centrifugation at $1500 \mathrm{~g}$ for 30 minutes, was stored at $-70^{\circ} \mathrm{C}$ until use. ${ }^{14} \mathrm{C}$-phenylethylamine (New England Nuclear, Boston, MA) was used to assay MAO-B activity according to the procedure of Young et al.$^{34}$

The determination of serotonin uptake in platelets was by the procedure of Johnson and Knowles. ${ }^{35}$ The PRP was diluted to the desired concentration with Tyrode-albumin solution, and $0.02 \mathrm{ml}$ aliquots were incubated with ${ }^{14} \mathrm{C}$-serotonin (final concentration 
approximately $5 \times 10^{-7} \mathrm{M}$ ) and Tyrode-albumin buffer at $37^{\circ} \mathrm{C}$ for 10 minutes. The reaction was stopped by addition of $0.5 \mathrm{ml}$ ice cold Tyrode's solution containing $0.2 \%$ EDTA. The tubes were centrifuged immediately at $2000 \mathrm{~g}$ for 10 minutes at $4^{\circ} \mathrm{C}$. After centrifugation, the supernatant was removed, the insides of the tubes were wiped with tissue, and the pellets dissolved with $0.2 \mathrm{ml}$ of $0.4 \mathrm{M}$ perchloric acid. The contents of the tubes were shaken, frozen, and thawed twice by immersion into liquid nitrogen and centrifuged. Aliquots of the supernatant liquid were then assayed for radioactivity.

Lymphocytes for the sigma receptor binding assay were separated from venous blood according to the method of Boyum, ${ }^{36}$ as described previously by Costa et al ${ }^{37}$ After centrifugation at $400 \mathrm{~g}$ for $\mathbf{3 0}$ minutes, the lymphocyte layer was transferred to another plastic centrifuge tube, resuspended in $10 \mathrm{ml}$ of Hank's buffer, washed three times by centrifugation at $200 \mathrm{~g}$ for 10 minutes, and resuspended in the same buffer. Lymphocytes were counted with a Coulter counter. Sigma receptor binding was performed with three ligands: ${ }^{3} \mathrm{H}$-ditoluylguanidine (DTG), ${ }^{3} \mathrm{H}$ spiperone, the ligand used in the previous study of boat plant workers, and ${ }^{3} \mathrm{H}$-haloperidol. All ligands gave similar results. Only the results pertaining to ${ }^{3} \mathrm{H}$-DTG binding are presented, however, because ${ }^{3} \mathrm{H}-\mathrm{DTG}$ is considered to be the most specific of the three ligands for sigma receptors. ${ }^{24}$ Binding of ${ }^{3} \mathrm{H}$ DTG was determined by incubating $1 \times 10^{6}$ cells at $37^{\circ} \mathrm{C}$ in $1 \mathrm{ml}$ of Hank's buffer in the presence (nonspecific binding) or absence (total binding) of $10 \mu \mathrm{M}$ ${ }^{3} \mathrm{H}$-haloperidol. After 30 minutes of incubation, samples were filtered through Whatman G/C filters, presoaked in $1 \%$ polyethylenimine, and washed three times with $3 \mathrm{ml}$ of ice cold phosphate buffered saline. The filters were air dried and transferred to polyethylene vials containing $10 \mathrm{ml}$ Safety Solve, and radioactivity was counted in a Beckman LS $5000 \mathrm{CE}$ scintillation spectrometer. A single concentration of ${ }^{3} \mathrm{H}-\mathrm{DTG}$ (30 $\mathrm{nM}$, corresponding to its dissociation constant, $K_{d}, 24$ ) was used in all assays.

\section{DATA ANALYSIS}

The principal methods of analysis of the data on neurochemical function involved Pearson and rank order correlations, and comparisons of means between groups. Mean values, adjusted for potentially confounding variables, were also compared on a group basis. Covariates included age, race, sex, years of employment, smoking (smokers $v$ non-smokers), and alcohol consumption (drinks per week).

Comparisons of prevalence of nervous system symptoms were restricted to simple contrasts of prevalence expressed in percentages. Throughout the analysis testing of statistical significance was deemphasised owing to the largely exploratory nature of the study.

\section{Results}

\section{SUBJECT CHARACTERISTICS}

Study subjects were classified into four groups, the reference workers, and three groups defined by blood styrene concentration $(<0 \cdot 05,0 \cdot 05-0 \cdot 19$, and $\geqslant 0 \cdot 20$ $\mu \mathrm{g} / \mathrm{ml}$ ). Category boundaries were chosen to give roughly similar numbers in the four groups while maintaining dispersion in the distribution of blood styrene. Blood styrene concentration was used as the exposure index, rather that air concentrations or urine metabolite concentrations, under the assumptions that blood concentrations would provide the best indicator of burden from recent exposures, and would probably exert the strongest effects on peripheral blood cells (findings were similar when analyses were performed with air styrene or urine metabolite concentrations). Table 1 gives the summary data on demographic variables, smoking, alcohol use, and exposure characteristics for the four exposure groups. The distributions of age, race, alcohol consumption, and duration of employment (especially among workers exposed to styrene) were similar between groups, although there was a higher proportion of women among the most heavily exposed workers. Differences in these factors were evaluated by covariance adjustments.

Table 1 Demographic lifestyle and exposure characteristics of blood styrene groups

\begin{tabular}{|c|c|c|c|c|}
\hline & \multicolumn{4}{|c|}{ Blood styrene conc ( $\mu \mathrm{g} / \mathrm{ml})$} \\
\hline & Non-exposed & $<0.05$ & $0.05-0.19$ & $\geqslant 0.20$ \\
\hline $\begin{array}{l}\text { No of subjects } \\
\% \text { Men } \\
\% \text { Caucasian } \\
\text { Age^ } \\
\% \text { Smokers } \\
\text { Drinks per week } \\
\text { Years employed }{ }^{\star} \\
\text { Styrene exposure (ppm) }\end{array}$ & $\begin{array}{l}18 \\
78 \\
88 \\
32 \cdot 6(2 \cdot 2) \\
22 \\
2 \cdot 5(0 \cdot 8) \\
6 \cdot 4(1 \cdot 7) \\
\text { ND† }\end{array}$ & $\begin{array}{l}17 \\
82 \\
86 \\
33 \cdot 5(1 \cdot 5) \\
18 \\
3.4(1 \cdot 3) \\
4 \cdot 0(1 \cdot 1) \\
10 \cdot 8(4 \cdot 9)\end{array}$ & $\begin{array}{l}27 \\
81 \\
96 \\
28 \cdot 5(1 \cdot 4) \\
54 \\
4 \cdot 3(0 \cdot 8) \\
3.4(0 \cdot 8) \\
18.9(3 \cdot 6)\end{array}$ & $\begin{array}{l}16 \\
50 \\
73 \\
35 \cdot 7(2 \cdot 0) \\
56 \\
2 \cdot 8(0 \cdot 9) \\
4 \cdot 1(1 \cdot 3) \\
50 \cdot 0(11 \cdot 1)\end{array}$ \\
\hline
\end{tabular}

*Mean (SE)

†None detected. 
Table 2 Prevalence (\%) of central nervous system symptoms by blood styrene concentration

\begin{tabular}{lllll}
\hline & \multicolumn{4}{l}{$B l o o d$ styrene conc $(\mu g / \mathrm{ml})$} \\
\cline { 2 - 5 } Symptom & $\begin{array}{l}\text { Non- } \\
\text { exposed }\end{array}$ & $<0.05$ & $0.05-0.19$ & $\geqslant 0.20$ \\
\hline Headache & $38.9 \star$ & 33.3 & 65.4 & 60.0 \\
Dizziness & 5.6 & 0 & 43.5 & 33.3 \\
Light headedness & 16.7 & 0 & 75.0 & 60.0 \\
Fatigue & 11.1 & 7.1 & 76.9 & 33.3 \\
Irritability & 22.2 & 14.3 & 83.3 & 71.4 \\
Feeling "drunk" at work & 11.1 & 7.1 & 26.1 & 42.9 \\
Memory loss & 22.2 & 28.6 & 40.0 & 40.0 \\
\hline
\end{tabular}

* Per cent of subjects reporting one or more episodes per week.

PREVALENCE OF NERVOUS SYSTEM SYMPTOMS

The questionnaire included questions about the number of times a week subjects experienced symptoms related to toxicity of the central nervous system. Increasing exposure related gradients of prevalence of symptoms, defined as the usual occurrence one or more times a week, were detected for headache, dizziness, light headedness, memory loss, and feeling "drunk" at work (table 2). The number of reported symptoms also increased with exposure (table 3 ). The possibility of confounding from age, sex, alcohol, smoking, and duration of employment was evaluated using multiple logistic regression analysis, and the results (not shown) were not materially different from those presented in tables 2 and 3.

\section{NEUROCHEMICAL FUNCTION PARAMETERS}

Table 4 gives the unadjusted and adjusted (for the previously mentioned covariates) mean values of MAO-B activity, serotinin uptake, and sigma receptors by exposure group. Also shown are median values of these parameters, which were contrasted as a check on potential undue influences of extreme values on intergroup comparisons of means. Contrary to previous findings of sigma receptor binding
Table 3 Number of central nervous system symptoms by blood styrene group

\begin{tabular}{lllll}
\hline & \multicolumn{4}{l}{ Blood styrene conc $(\mu \mathrm{g} / \mathrm{ml})$} \\
\cline { 2 - 5 } Number of CNS symptoms & $\begin{array}{l}\text { Non- } \\
\text { exposed }\end{array}$ & $<0.05$ & $0.05-0.19$ & $\geqslant 0.20$ \\
\hline 0 & $38.9 \dagger$ & 53.3 & 11.5 & 6.7 \\
1 & 33.3 & 26.7 & 11.5 & 26.7 \\
2 & 11.1 & 6.7 & 11.5 & 6.7 \\
$\geqslant 3$ & 16.7 & 13.3 & 65.4 & 60.0 \\
\hline
\end{tabular}

*Symptoms include headache, dizziness, light headedness, fatigue, irritability, memory loss, feeling "drunk" at work.

†Per cent of subjects in blood styrene group.

among fibreglass reinforced plastic boat plant workers, ${ }^{23}$ these data suggest no consistent effect of exposure. The trend for uptake of serotonin was a weak increasing gradient, which appeared most prominently from comparisons of median values. The most striking finding was an inverse association between blood styrene concentration and MAO-B activity; inverse gradients were found for unadjusted and adjusted means, as well as for median values. Table 5 gives the simple Pearson and rank order correlations between blood styrene concentration and the neurochemical parameters. The negative correlations with unadjusted and adjusted MAO-B activity values were not large (ranging from -0.22 to -0.38 ), suggesting that relatively little of the variance of this parameter could be explained by exposure to styrene.

Associations between prevalence of symptoms and parameters of neurochemical function were assessed by comparing adjusted mean values between subject groups classified by the number of reported CNS symptoms (table 6). Sigma receptor binding and serotonin uptake were both unrelated to symptoms, whereas there was an inverse trend with MAO-B activity. Similar findings were seen when unadjusted

Table 4 Peripheral blood cell markers of neurochemical function by blood styrene concentration

\begin{tabular}{|c|c|c|c|c|}
\hline \multirow[b]{2}{*}{ Parameter/blood cell (units) } & \multicolumn{4}{|c|}{ Blood styrene conc $(\mu \mathrm{g} / \mathrm{ml})$} \\
\hline & Non-exposed & $<0.05$ & $0.05-0.19$ & $\geqslant 0.20$ \\
\hline $\begin{array}{l}\text { Serotonin uptake by platelets (pmol/10 } 10^{7} \text { cells/min): } \\
\text { Mean (SE) } \\
\text { Adjusted mean (SE) } \\
\text { Median }\end{array}$ & $\begin{array}{l}43 \cdot 9(11 \cdot 2) \\
34 \cdot 3(3 \cdot 6) \\
39 \cdot 4\end{array}$ & $\begin{array}{l}58 \cdot 2(4 \cdot 5) \\
58 \cdot 6(5 \cdot 8) \\
53 \cdot 9\end{array}$ & $\begin{array}{l}45 \cdot 4(4 \cdot 9) \\
48 \cdot 2(5 \cdot 7) \\
46 \cdot 6\end{array}$ & $\begin{array}{l}49 \cdot 4(5 \cdot 8) \\
49 \cdot 5(6 \cdot 5) \\
56 \cdot 7\end{array}$ \\
\hline
\end{tabular}

$\star$ Adjusted for age, race, sex, years of employment, alcohol intake (drinks per week), smoking (smokers $v$ non-smokers). 
Table 5 Correlations between blood styrene concentration and peripheral markers of neurochemical function

\begin{tabular}{lll}
\hline & \multicolumn{2}{l}{ Correlation coefficient $(r)$} \\
\cline { 2 - 3 } Parameter & Pearson & Rank order \\
\hline Sigma receptors & -0.02 & -0.02 \\
Sigma receptors (adjusted) $\dagger$ & +0.08 & -0.15 \\
Monoamine oxidase B & $-0.28^{\star}$ & $-0.38^{\star}$ \\
Monoamine oxidase B (adjusted) & -0.22 & -0.29 \\
Serotonin uptake & +0.06 & +0.20 \\
Serotonin uptake (adjusted) & +0.04 & $+0.21^{\star}$ \\
\hline
\end{tabular}

†Adjusted for age, race, sex, years of employment, smoking, alcohol intake.

${ }^{\star} \mathrm{p}<0.05 ;{ }^{\star \star} \mathrm{p}<0.01$.

means or medians were compared. The inverse association between MAO-B activity and frequency of CNS symptoms is not unexpected in view of the increasing prevalence of symptoms related to exposure, and the inverse relation between exposure and MAO-B activity. None the less, the association between symptoms and MAO-B activity suggests the possibility that MAO-B may be involved as an intermediate step in styrene induced CNS neurotoxicity.

\section{Discussion}

There is a growing trend in occupational health research to identify readily accessible biological markers of effects from toxic chemical exposures. This strategy is particularly pertinent to the study of neurotoxicity when ethical and feasibility constraints preclude direct measurements of exposure related biochemical changes in the target organs.

This study was an attempt to apply some biomarkers of neurochemical function to an epidemiological study of workers exposed to a well known neurotoxicant, styrene. Some previous experimental data suggest that MAO-B activity and serotonin uptake might be influenced by exposure to styrene, ${ }^{18}$ although previous experience with these assays in occupational groups is limited or non-existent. The results for sigma receptor binding were unremarkable, indicating that this may not be an especially relevant parameter for styrene related neurotoxicity. Increased uptake of serotonin in platelets has been proposed as a marker of effects of solvent exposure, ${ }^{22}$ although only slight increases related to exposure were found in this study. The negative trend of
MAO-B activity with exposure to styrene is consistent with previously reported experimental findings in animals, ${ }^{18}$ and the consistent decreases in MAO-B activity in workers experiencing CNS symptoms suggest a potential neurotoxic mechanism involving MAO-B activity and metabolic disturbances of dopamine and other bioactive amines. Currently no clear hypotheses explain the mechanism(s) of styrene effects on MAO-B activity. Styrene might exert a direct inhibitory effect on the enzyme; alternatively, changes in MAO-B activity could represent an adaptative response to a primary dopamine depletion induced by exposure. Further in vitro and in vivo animal studies should consider the validity of platelet MAO-B measurement as an index of MAO-B activity in the central nervous system, and should focus on elucidating mechanisms of styrene induced alterations.

Some of the limitations of this study that complicate the interpretation of the data are the small numbers of exposed subjects and the cross sectional design, which restricts causal inference, especially in studies of biomarkers of effect. Also, for convenience, blood samples for styrene measurements were obtained during the early hours of the workshift rather than at the optimal time, which would be at the end of the shift. ${ }^{38}$ Finally, in the absence of a clear understanding of toxic mechanisms, the directions of biomarker trends in relation to degree of exposure will necessarily be difficult, if not impossible, to predict.

The results from this study indicate that MAO-B activity may be a useful biomarker of effect of occupational exposure to styrene. Further studies of MAO-B activity and other biomarkers of neurochemical function on larger study populations exposed to styrene, and perhaps other organic solvents, should indicate which markers offer the greatest promise for application in biomonitoring programmes. Repeated measurements of exposure and biomarkers of neurochemical function over time will be important for assessing the stability of associations found.

This research was supported by grants from the National Institute for Occupational Safety and Health (OH-02629), the National Institute for Environmental Health Sciences (ES-04696), and the

Table 6 Peripheral blood cell markers of neurochemical function by number of CNS symptoms reported

\begin{tabular}{|c|c|c|c|c|}
\hline \multirow[b]{2}{*}{ Parameter/cell } & \multicolumn{4}{|c|}{ No of CNS symptoms * } \\
\hline & $0(n=19)$ & $1(n=17)$ & $2(n=7)$ & $\geqslant 3(n=31)$ \\
\hline $\begin{array}{l}\text { Sigma receptor binding by lymphocytes }\left(\mathrm{fmol} / 10^{6} \mathrm{cells}\right) \\
\left.\text { MAO-B activity on platelets ( } \mathrm{pmol} / 10^{7} \mathrm{cells} / \mathrm{min}\right) \\
\text { Serotonin uptake by platelets }\left(\mathrm{pmol} / 10^{7} \mathrm{cells} / \mathrm{min}\right)\end{array}$ & $\begin{array}{l}84 \cdot 7(10 \cdot 3) \dagger \\
26 \cdot 4(18 \cdot 2) \\
51 \cdot 0(5 \cdot 6)\end{array}$ & $\begin{array}{l}97 \cdot 7(10 \cdot 8) \\
46 \cdot 4(10 \cdot 3) \\
43 \cdot 4(6 \cdot 7)\end{array}$ & $\begin{array}{l}90.7(12.4) \\
16.9(11 \cdot 7) \\
46.5(3.9)\end{array}$ & $\begin{array}{r}81 \cdot 9(8 \cdot 0) \\
5 \cdot 5(3 \cdot 7) \\
50 \cdot 0(4 \cdot 6)\end{array}$ \\
\hline
\end{tabular}

*Symptoms include headache, dizziness, light headedness, fatigue, irritability, feeling "drunk" at work, memory loss.

† Mean (SE) adjusted for age, race, sex, years of employment, alcohol use, smoking. 
Fondazione Clinica del Lavoro (Pavia, Italy). We are grateful to Tammy Ennen, Kristy Loreen, Brian McDonald, and Joseph Picciano for technical assistance, and to Martha Finley for manuscript preparation.

Requests for reprints to: Harvey Checkoway, $\mathrm{PhD}$, Department of Environmental Health, SC-34, University of Washington, Seattle, WA 98195, USA.

1 Harkonen H. Relationships of symptoms to occupational styrene exposure and to the findings of electroencephalographic and psychological evaluations. Int Arch Occup Environ Health 1977;40:231-9.

2 Lorimer WV, Lilis R, Fischbein A, et al. Health status of styrene-polystyrene polymerization workers. Scand JWork Environ Health 1978;4 (suppl 2):220-6.

3 Lilis R, Lorimer WV, Diamond S, Selikoff IJ. Neurotoxicity of styrene in production and polymerization workers. Environ Res 1978;15:133-8.

4 Gottell O, Axelson O, Lindehof B. Field studies on human styrene exposure. Work Environ Health 1972;9:76-83.

5 Cherry N, Waldron HA, Wells GG, et al. An investigation of the acute behavioural effects of styrene in factory workers. $\mathrm{Br} \mathrm{J}$ Ind Med 1980;37:234-40.

6 Cherry N, Rogers B, Venables H, et al. Acute behavioural effects of styrene exposure: a further analysis. $\mathrm{Br} J$ Ind Med $1981 ; 38: 346-50$.

7 Lindstrom $\mathrm{K}$, Harkonen $\mathrm{H}$, Hernberg S. Disturbances in psychological functions of workers occupationally exposed to styrene. Scand J Work Environ Health 1976;3:129-39.

8 Harkonen H, Lindstrom K, Seppalainen AM, Asp S, Hernberg $S$. Exposure-response relationships between styrene exposure and central nervous functions. Scand $J$ Work Environ Health 1978;4 (suppl 2):104-13.

9 Seppalainen AM, Harkonen H. Neurophysiological findings among workers occupationally exposed to styrene. Scand Work Environ Health 1976;3:140-6.

10 Triebig G, Lehrl S, Welte D, Schaller KH, Valentin H. Clinical and neurobehavioural study of the acute and chronic neurotoxicity of styrene. Br J Ind Med 1989;46:799-804.

11 Flodin U, Ekberg K, Andersson L. Neuropsychiatric effects of low exposure to styrene. $\mathrm{Br} J$ Ind Med 1989;46:805-8.

12 Arfini G, Mutti A, Vescovi P, et al. Impaired dopaminergic modulation of pituitary secretion in workers occupationally exposed to styrene: further evidence from PRL response to TRH stimulation. $J$ Occup Med 1987;29:826-30.

13 Mutti A, Romanelli A, Falzoi M, Lucertini S, Franchini I Styrene metabolism and striatal depletion in rabbits. Arch Toxicol 1985;56 (suppl 8):447-50.

14 Romanelli A, Falzoi M, Mutti A, Bergamaschi E, Franchini I. Effects of some monocyclic aromatic solvents and their metabolities on brain dopamine in rabbits. J Appl Toxicol 1986;6:431-5.

15 Zaidi N, Agrawal AK, Srivistava SP, Seth SP. Effect of gestational and neonatal styrene exposure on dopamine receptors. Neurobehav Toxicol Teratol 1985;7:23-8.

16 Mutti A, Vescovi PP, Falzoi M, Arfini G, Valenti G, Franchini I. Neuroendocrine effects of styrene on occupationally exposed workers. Scand J Work Environ Health 1984;10:225-8.

17 Stahl SM. Peripheral models for the study of neurotransmitte receptors in man. Psychopharmacol Bull 1985;21:663-71.

18 Husain R, Srivastava SP, Mushtag M, Seth PK. Effect of styrene on levels of serotonin, noradrenaline, dopamine, and activity of acetyl cholinesterase and monoamine oxidase in rat brain. Toxicol Lett 1980;7:47-50.

19 Vandermaelen CP. Serotonin. In: Rogawski MA, Baker JL, eds. Neurotransmitte actions in the vertebrate nervous system. New York: Plenum Press, 1985:201-40.

20 Bosin TR. Oxidative stress stimulates active transport of serotonin by platelets. J Pharmacol Exp Ther 1989;248:67-72.

21 Beving H, Kristensson J, Malmgren R, Olsson P, Unge G. Effect on the uptake kinetics of serotonin (5-hydroxytryptamine) in platelets from workers with long-term exposure to organic solvents: a pilot study. Scand J Work Environ Health 1984;10:229-34.

22 Lam HR, Tarding F, Stockholm J, Gyatelberg F. Human platelet 5-hydroxytryptamine concentration as a tool in the prediction of solvent induced neurotoxic effects. Acta Pharmacol Toxicol 1985;56:233-8.

23 Checkoway H, Costa LG, Coccini T, Rappaport SM, Manzo L. Monitoring styrene neurotoxicity with ${ }^{3} \mathrm{H}$-Spiperone. In Sakurai H, Okazaki I, Omae K, eds. Occupational epidemiology: proceedings of the seventh international symposium on epidemiology in occupational health, Tokyo, Japan, October, 1989. Amsterdam: Excerpta Medica, 1990:197-200.

24 Coccini T, Manzo L, Costa LG. ${ }^{3} \mathrm{H}$-Spiperone labels sigma receptors, not dopamine $D_{2}$ receptors, in rat and human lymphocytes. Immunopharmacology 1991;22:93-106.

25 Deutsch SI, Weizman A, Goldman ME, Morihisa JM. The sigma receptor: a novel site implicated in psychosis and antipsychotic drug efficacy. Clin Neuropharmacol 1988;11:105-19.

26 Izhak Y, Stein J. Sigma receptor binding sites in the brain: an emerging concept for multiple sites and their relevance for psychiatric disorders. Life Sci 1990;47:1073-81.

27 White DM, Daniell WE, Maxwell JK, Townes BD. Psychosis following styrene exposure: a case report of neuropsychological sequelae. J Clin Exp Neuropsychol 1990;12 798-806.

28 National Institute for Occupational Safety and Health. Manual of laboratory methods. Washington, DC: Government Printing Office, 1985.

29 Guilleman M, Bauer D. Human exposure to styrene. II Quantitative and specific gas chromatographic analysis of urinary mandelic and phenylglyoxylic acids as an index of styrene exposure. Int Arch Occup Environ health 1976;37: $57-64$.

30 Dills RL, Wu RL, Checkoway H, Kalman DA. Capillary gas chromatographic method for mandelic and phenylglyoxylic acids in urine. Int Arch Occup Environ Health 1991;62:603-6.

31 Dills RL, Kent SD, Checkoway H, Kalman DA. Quantitation of volatile solvents in blood using static headspace analysis. Talanta 1991;38:365-74.

32 Hamet P, Fraysse T, Franks DL. Cyclic nucleotides and aggregation of platelets of spontaneously hypertensive rats. Circ Res 1978;43:583-91.

33 Corash L, Shafer B, Perlow M. Heterogeneity of human whole blood platelet subpopulations. II. Use of a subhuman primate model to analyze the relationship between density and platelet age. Blood 1979;52:726-34.

34 Young WF, Laws ER, Sharbrough FW, Weinshilboum RM Human monoamine oxidase-lack of brain and platelet correlation. Arch Gen Psychiatry 1986;43:604-9.

35 Johnson TL, Knowles CO. Inhibition of rat platelet 5-hydroxytyptamine uptake by chlordimeform. Toxicol Lett 1981 9:1-4.

36 Boyum A. Isolation of mononuclear cells and granulocytes from human blood. Scand J Clin Lab Invest 1968;21 (suppl 97): 77-89.

37 Costa LG, Kaylor G, Murphy SD. Muscarinic cholinergic binding sites on rat lymphocytes. Immunopharmacology 1988;16:139-49.

38 Guillemin MP, Berode M. Biological monitoring of styrene: a review. Am Ind Hyg Assoc J 1988;49:497-505.

Accepted 4 November 1991 